\title{
Towards Zero Energy Districts developments base on bioclimatic strategies: A Numerical Study in a Developing Country
}

\author{
Lissette De León ${ }^{1}$, Miguel Chen Austin ${ }^{1,3}$, Cristina Carpino $^{2}$ and Dafni Mora ${ }^{1,3^{*}}$ \\ ${ }^{1}$ Faculty of Mechanical Engineering, Universidad Tecnológica de Panamá, Ciudad de Panamá, Panamá \\ 2 Department of Mechanical, Energy and Management Engineering, University of Calabria, Via P. \\ Bucci, 87036 Arcavacata di Rende (CS), Italy \\ ${ }^{3}$ Centro de Estudios Multidisciplinarios en Ciencias, Ingeniería y Tecnología (CEMCIT-AIP), Ciudad \\ de Panamá, Panamá
}

\begin{abstract}
The need for more efficient buildings to contribute to more sustainable development has led to the establishment of targets in different countries. European countries have presented energy plans to respond to the guidelines of achieving near-zero energy buildings (nZEB). The concept can be defined at the urban scale (nZED), being a delimited part of a city with high energy efficiency and using renewable energies within its boundaries. This research aims to carry out a numerical study in a residential development in Panama, based on a proposal to redesign it, but using bioclimatic strategies and implementing photovoltaic technology. Thus, to evaluate the feasibility of nZED in the region and to function as a preliminary study to implement regulations of this type in the country. The results indicate that the indoor comfort conditions of each residential building should be evaluated in greater depth, and energy savings of $40 \%$ were obtained by implementing the recommended bioclimatic strategies and becoming independent of air conditioning equipment. In addition, photovoltaic generation outstrips demand, making the development net energy positive.
\end{abstract}

\section{Introduction}

As a result of the growing interest in achieving sustainable development, the drive for standards and the establishment of global and local goals have arisen, depending on the policies of each country. One perspective to achieve such sustainability is reducing energy use and the generation of greenhouse gases, focusing on the building area since the use of construction or remodeling techniques to obtain efficient buildings has been shown to be a powerful gradual tool to mitigate the environmental effects caused by urban projects.

The National Energy Plan (PEN 2015-2050) involves in its objectives the improvement of energy efficiency in buildings, based on the existing concern about the intensive use of air

\footnotetext{
* Corresponding author: dafni.mora@utp.ac.pa
} 
conditioning equipment and closed environments with little natural lighting [1]. Likewise, since 2019, the Sustainable Buildings Regulation (RES) has been in force, which establishes a series of requirements such as transmittance of materials (U-value), window-wall ratio and COP of HVAC equipment, to promote new residential and non-residential high-performance buildings, both in the public and private sectors, establishing energy savings percentages of $15 \%$ to $20 \%$ [2].

On the other hand, the member countries of the European Union have presented national plans where they define their local targets to achieve near-zero energy buildings (nZEB) and respond to the guidelines of the Energy Performance of Buildings Directive (EPBD) [3] . An nZEB is defined as a more achievable goal of a NZEB (net zero balance) and is known as a building that requires very low energy for its operation and uses renewable energy to supply part of the demand. The "near" concept will depend on the optimal costs, the percentage of renewable energy to be used, and the level of ambition of each country [4]. This approach has also given way to studying and implementing at the urban or district scale (called nZED), defined as a delimited part of a city or urban block with very high energy yields $[5,6]$.

A literature review was conducted to know the criteria and parameters that are analyzed to achieve urbanizations with near-zero or net-zero performance, which are briefly described.

A study at NZEB (Net Zero Energy Building) scale in Colombia indicates that for hot climates, the optimal orientation should be North-South, and although it emphasizes some passive techniques such as natural ventilation and the use of skylights for natural lighting, it suggests that the efficiency of active systems should have greater relevance due to their great impact on energy consumption [7].

In [8], it is recognized that morphology, energy performance, and solar energy potential have an essential relationship between buildings and urban areas. Similarly, Amaral et al. [5] indicate that complex urban morphologies lead to microclimates, leading to an increase in temperature and, therefore, cooling consumption. Finally, Cabeza and Chàfer [9] suggest that the design of a zero-energy building should analyze several scenarios based on multiobjective optimization, and focus on bioclimatic construction to improve indoor comfort, having as an effect the independence of HVAC equipment and lighting.

From another perspective, the authors in [10] describe that the little consideration of the occupants' behavior is one of the main reasons for the discrepancy between the real consumption and the one obtained in the dynamic simulations, which can lead to catalog buildings as zero energy without actually being zero energy when the buildings are occupied and start to operate.

For energy generation, studies such as $[7,11]$ indicate that photovoltaic integration and application could be the most suitable source in hot climates. Some applications found in the current literature to achieve zero-energy housing developments take as a reference the use of passive strategies (based on bioclimatic architecture) and the evaluation of these through dynamic simulations. In Valladolid, Spain, a district evaluated remodeling of the facades and roofs, but more emphasis is placed on replacing the heating system based on fossil fuels with a biomass-based one and covering $25 \%$ of the demand with a photovoltaic system [12]. On the other hand, the authors in [11] focus on analyzing urban design parameters such as orientation, distance between buildings, floor area ratio, and form factors to assess their influence on thermal performance in an nZED framework. Other studies focus on optimization for the reduction of energy consumption, costs, and $\mathrm{CO} 2$ emissions by selecting variables such as orientation, insulation, and type of artificial lighting [13].

The present numerical study investigates the nZED potential of a residential development in a humid tropical climate region by applying bioclimatic strategies and using photovoltaic panels for on-site energy generation. The thermal comfort of occupants in buildings is also considered, which sometimes is excluded from the analysis. Following a bioclimatic philosophy could benefit both the reduction of consumption by facilitating the achievement 
of a balance close to zero and compliance with thermal comfort indicators. With this work, we contribute to the literature in similar climates and the Latin American region since studies currently focus on the building level. In addition, the most important thing is to establish the methodology in Panama and promote the creation of policies.

\section{Methodology}

To fulfill the main objective of this work, which is to study the possibility of obtaining nZED in a residential development, taking into account bioclimatic strategies using dynamic simulation, it is necessary to i) know the climate of the region, create the $3 \mathrm{D}$ model considering the envelope and the occupancy and equipment use profiles, ii) carry out a bioclimatic analysis and apply the most convenient strategies for the region and finally iii) evaluate the reduction of consumption, the comfort conditions and make the energy balance in terms of primary energy.

The methodology used is summarized in Figure 1. First, a 3D model of an existing residential development (hereafter referred to as ED) was created in DesignBuilder 6.1.6.011 software to evaluate its conditions in terms of energy consumption and thermal comfort. Subsequently, we proceed to design a new urbanization where the implementation of bioclimatic strategies (redesigned case, called BD) is considered, seeking first to reduce energy consumption and then to implement renewable generation technologies on the site. Both cases were evaluated under the same climatic conditions, in an area of the district of Chitré, province of Herrera in the Republic of Panama, whose climate is tropical humid-dry (Awi climate type according to Köppen classification). According to Solargis meteorological data $\mathrm{C}$, the study site has an average annual temperature of $27.2^{\circ} \mathrm{C}$ and relative humidity of $78 \%$. Panama has two seasons throughout the year: dry (January to March) and rainy (April to December), with the hottest conditions occurring in March.

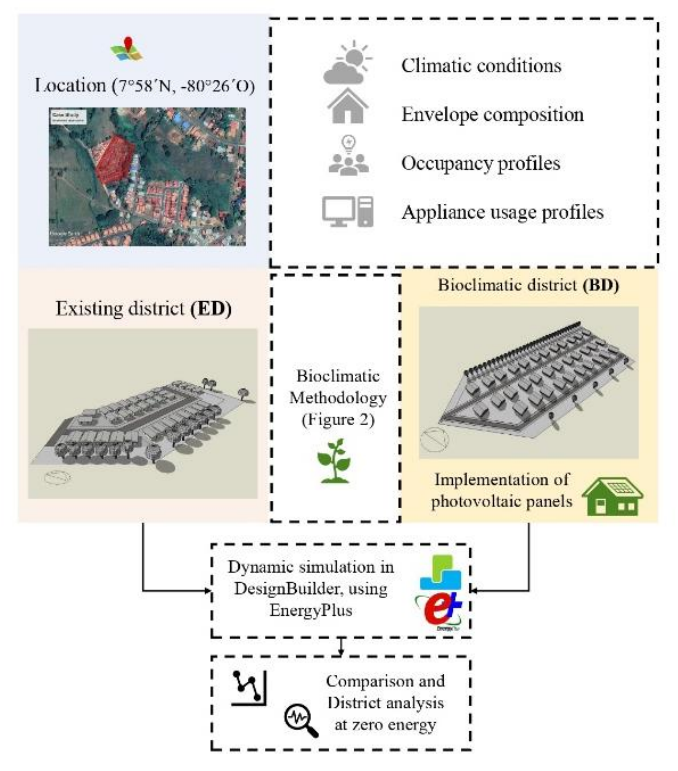

Fig. 1. Methodology used in the zero-energy district analysis. 


\section{Numerical Model}

\subsection{Case study}

The ED model comprises 34 houses with $55 \mathrm{~m}^{2}$, distributed on a 1.13-hectare site. Since these houses were built between 2016 and 2019, parameters linked to RES regulation were not considered. The architectural floor plan consists of six zones (portal, two bedrooms, living room, kitchen, and bathroom). For the modeling, the construction materials currently used in the building were taken into consideration: concrete walls (U-value of $4.01 \mathrm{~W} / \mathrm{m}^{2} \mathrm{~K}$ ), zinc roof (U-value of $\left.7.14 \mathrm{~W} / \mathrm{m}^{2} \mathrm{~K}\right)$ and single glazed windows with a solar gain coefficient of 0.77 (U-value of $3.84 \mathrm{~W} / \mathrm{m}^{2} \mathrm{~K}$ ). Occupancy profiles were obtained from a survey applied to residents in January and February 2021, obtaining a response rate of $45 \%$. For the residences that did not respond to the survey, standard schedules from DesignBuilder software were used. A summary of the results is presented in Table 1 .

Table 1. Summary of the main characteristics of occupancy profiles and energy in the entire residential development.

\begin{tabular}{|c|c|c|}
\hline Description & From survey (16 answered) & Standard (18 not answered) \\
\hline Occupancy & $\begin{array}{ll}\text { - } & 1 \text { to } 5 \text { people } \\
\text { - } & \text { Schedule: } 24 / 7\end{array}$ & $\begin{array}{ll}\text { - } & 4 \text { people (from [14]) } \\
\text { - } & \text { Schedule: } 24 / 7\end{array}$ \\
\hline $\begin{array}{c}\text { Air conditioner AC } \\
\text { (Split units) }\end{array}$ & $\begin{array}{l}\text { - } \quad \text { A total of } 7 \mathrm{AC} \text { units } \\
\text { - } \quad \text { Setpoint temperature range: } \\
\text { 16-25 }{ }^{\circ} \mathrm{C} \text {. } \\
\text { - } \quad \text { COP: } 3.00 \\
\text { - } \quad \text { Relative humidity: } 60 \% \\
\text { - } \quad \text { Schedule: } 13: 00-9: 00\end{array}$ & $\begin{array}{l}\text { - } \text { A total of } 11 \mathrm{AC} \text { units } \\
\text { - } \quad \text { Setpoint temperature range: } \\
\text { 16-25 }{ }^{\circ} \mathrm{C} \text {. } \\
\text { - } \quad \text { COP: } 3.00 \\
\text { - } \quad \text { Relative humidity: } 60 \% \\
\text { - } \quad \text { Schedule: } 24: 00 \text { a } 9: 00\end{array}$ \\
\hline Natural ventilation & Schedule: 8:00-18:00 & $\begin{array}{l}\text { Schedule: } 7: 00-22: 00 / 23: 00- \\
7: 00\end{array}$ \\
\hline Lightning & 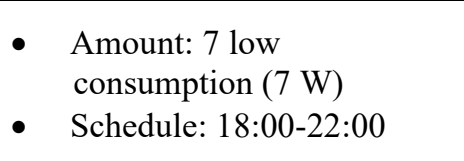 & $\begin{array}{l}\text { Amount: } 7 \text { low } \\
\text { consumption }(7 \mathrm{~W}) \\
\text { Schedule: } 10: 00- \\
\text { 19:00/23:00-24:00 }\end{array}$ \\
\hline Household & $\begin{array}{ll}\text { - } & \text { Fans }(150 \mathrm{~W}) \\
\text { - } & \text { Refrigerator }(52 \mathrm{~W}) \\
\text { - } & \mathrm{PC}(45 \mathrm{~W}) \\
\text { - } & \mathrm{TV}(76 \mathrm{~W}) \\
\text { - } & \text { Washing machines }(400 \mathrm{~W})\end{array}$ & $\begin{array}{ll} & \text { Fans }(150 \mathrm{~W}) \\
- & \text { Refrigerator }(52 \mathrm{~W}) \\
\text { - } & \text { PC }(45 \mathrm{~W}) \\
\text { - } & \mathrm{TV}(76 \mathrm{~W}) \\
\text { - } & \text { Washing machines }(400 \mathrm{~W})\end{array}$ \\
\hline
\end{tabular}

\subsection{Redesigned case}

For the redesign of the urbanization, a flow diagram was made (Figure 2) to systematize the bioclimatic methodology applied to this study and serve as a reference framework for future research. First, a climatic analysis of the site was carried out, analyzing variables such as temperature, humidity, precipitation, winds, and radiation. Then, an analysis of sunlight and wind on the facades of the lot was carried out, using the solar chart and the wind rose to determine the new orientation of the houses. Subsequently, to obtain the new architectural design, the analysis was supported by the Bioclimarq 2016 spreadsheet [15], analyzing temperatures and humidities, to obtain the results provided by Mahoney's questionnaire, 
Serra and Coch's form and skin treatment indicators, and Givoni and Olgyay's bioclimatic diagrams, which provide recommendations to improve indoor and outdoor conditions, respectively. Once the building design and layout have been obtained, the comfort conditions must be verified.

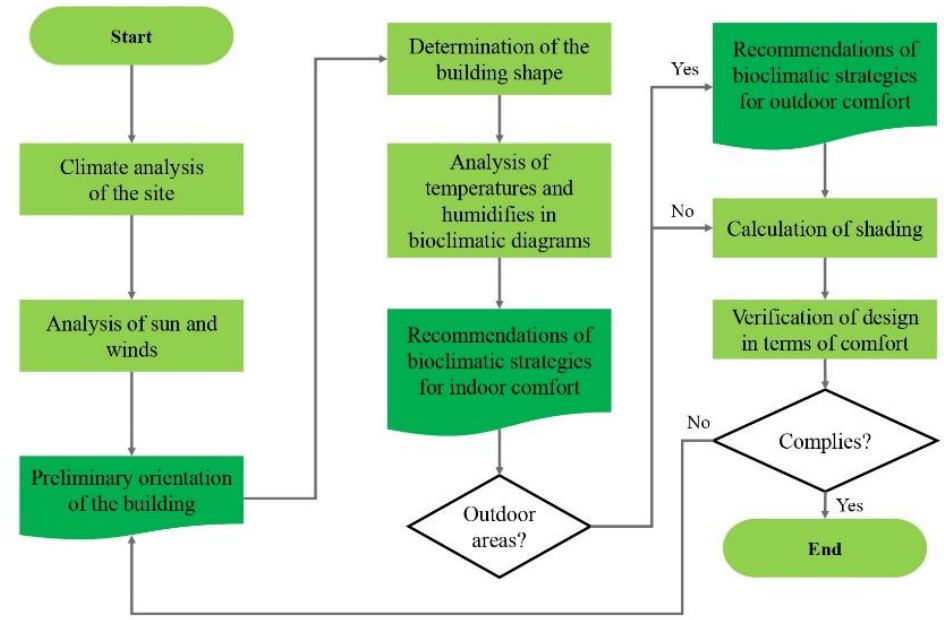

Fig. 2. Process diagram of the bioclimatic methodology.

The wind rose analysis indicated that the predominant wind direction for the study site is north, with speeds greater than $11.10 \mathrm{~m} / \mathrm{s}$. Therefore, the most favorable facades to promote natural and cross ventilation are those oriented to the north, south, and northeast of the lot. On the other hand, the solar chart indicates that the facades facing north are the ones that receive the highest solar incidence, so the use of solar protection should be considered, and due to the low solar height in the southeast, the use of eaves in this direction is also productive.

For the architectural design, Table 2 presents the main results obtained by applying the BD model based on the bioclimatic tables and diagrams used in this study.

To determine the materials to be used in the new design, a parametric analysis was performed in the DesignBuilder software, which aims to reduce the electrical consumption used for space cooling and maximize the hours of comfort in the buildings.

Table 2. Main passive recommendations obtained from bioclimatic tools.

\begin{tabular}{|c|c|}
\hline Bioclimatic approaches & Recommendations \\
\hline Mahoney & $\begin{array}{l}\text { 1. North-South orientation. } \\
\text { 2. Extended configuration. } \\
\text { 3. Spans in the predominant wind } \\
\text { direction. } \\
\text { 4. Total and permanent shading. }\end{array}$ \\
\hline Givoni & $\begin{array}{l}\text { 1. Daytime ventilation (up to } 2 \mathrm{~m} / \mathrm{s} \text { ). } \\
\text { 2. Dehumidification. } \\
\text { 3. Cooling and dehumidification. }\end{array}$ \\
\hline Olgyay & $\begin{array}{l}\text { 1. Natural ventilation }(0.5 \mathrm{~m} / \mathrm{s} \text { to } 2.5 \\
\mathrm{m} / \mathrm{s}) \text {. } \\
\text { 2. Shading. }\end{array}$ \\
\hline
\end{tabular}




\begin{tabular}{|l|ll|}
\hline \multirow{2}{*}{ Serra and Coch } & 1. & Decrease of compactness. \\
& 2. & Increase U-factor. \\
\hline
\end{tabular}

\subsection{Electricity generation system}

Photovoltaic technology was used for power generation at the site due to the solar availability in the region (annual average global radiation of 4.86 Peak Solar Hour (PSH) according to Solargis meteorological data (C) and because of the recommendations of the literature on zero energy applications in comparison with other types of energy used for generation in residential and nZED buildings. In addition, in [16], it is supported that there is a higher solar potential than wind in most of the country. Several polycrystalline photovoltaic panels (120) were implemented on the south-facing side of the roof of each building of case BD, considering a power of $320 \mathrm{~W}$ and an efficiency of $15 \%$. It should be noted that, as economic factors are not considered in this study, the number of panels is based on the higher generation that can be obtained with panels applied in an optimal orientation (southward) for Panama due to its location in the northern hemisphere [17].

\section{Results analysis and discussion}

In this section, we first present the main characteristics applied from the recommendations obtained through the bioclimatic methodology. Then we compare the performance of both districts, and, finally, we perform an energy balance in BD to obtain in numerical terms the net energy and establish the nZED feasibility.

The eaves dimensions used were $1 \mathrm{~m}$, calculated for solar protection up to 15:00. Additionally, Climate Consultant 6.0 software [18] was used to obtain bioclimatic strategies under the Givoni chart analysis, to improve indoor comfort, including: minimization of glazing on the west façade, high-performance glazing, orientation of most of the glazing to the north, and use of trees in the west direction, windows oriented to the prevailing breeze. The use of the following materials was suggested by the parametric analysis (not presented here): low emissivity double glazing ( $\mathrm{e}=0.1) 3 \mathrm{~mm} / 6 \mathrm{~mm}$ air ( $\mathrm{U}$ value of $2.47 \mathrm{~W} / \mathrm{m}^{2} \mathrm{~K}$ ), block or brick walls with super insulation ( $\mathrm{U}$ value of $0.156 \mathrm{~W} / \mathrm{m}^{2} \mathrm{~K}$ ), and as an active recommendation, setting the air conditioning temperature at $25^{\circ} \mathrm{C}$, with a schedule of 18:00 to 8:00, and no use during weekends. All the recommendations described above were used to propose the shape and distribution of the 34 houses of case BD (Figure 3). It should be noted that the shape of the lot was maintained. However, by decreasing the buildings' compactness and increasing the distance between them to promote natural ventilation, the lot size was increased to 10.2 hectares. Some concerns arise when considering super isolated walls, but this might be suggested by the parametric analysis since it was performed onto the ED, which has air conditioner units.

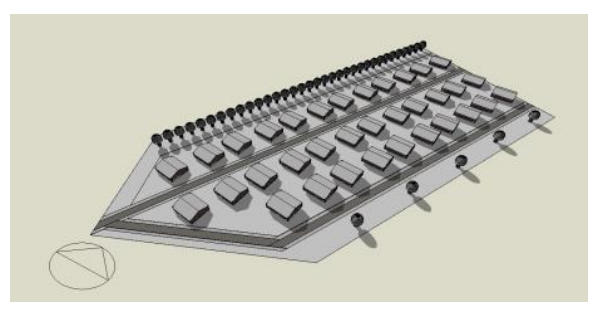

(a)

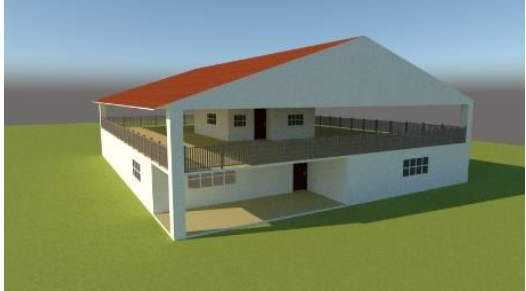

(b)

Fig. 3. Case BD: (a) distribution and orientation of the houses, (b) architectural design of the individual building. 


\subsection{Comparison of ED and BD}

Based on the simulation results, we first compared the equipment (EQ), cooling (AC), and lighting (LG) consumption of the $\mathrm{ED}$ and $\mathrm{BD}$ models. As expected, the demand for equipment and lighting remains constant since the occupant behavior for the BD case remained the same. However, as shown in Figure 4(a), air conditioning consumption increases by an annual average of $100 \%$ (double) for BD, because air conditioners were applied in the living room and bedrooms of 10 houses in $\mathrm{BD}$ model temperatures exceeded the comfort limits (greater than $28.5^{\circ} \mathrm{C}$ according to the national Sustainable Building Guide [19]). Although the cooling temperature and schedule settings for air conditioning obtained in the parametric analysis were applied (which should decrease demand), the consumption increase might be explained by the increase in air volume (each zone is larger due to the reduction of compactness).

An inquiry on comfort on an hourly basis was performed, and it was found that not all hours of the day present temperatures outside the comfort limit, which represents an opportunity to evaluate consumption by adjusting the schedule of air conditioning equipment to actual needs. However, it has been considered for the present investigation that no house uses air conditioning equipment since temperatures range between $1{ }^{\circ} \mathrm{C}$ and $2{ }^{\circ} \mathrm{C}$ higher than the maximum upper comfort limit. Finally, Figure 4(b) is a graphical comparison of the difference between the electricity consumption at the ED and BD case urbanization level, without considering cooling equipment in the latter, obtaining an average annual difference of $40 \%$. With 120 photovoltaic panels per building, generation was found to exceed consumption in both cases.

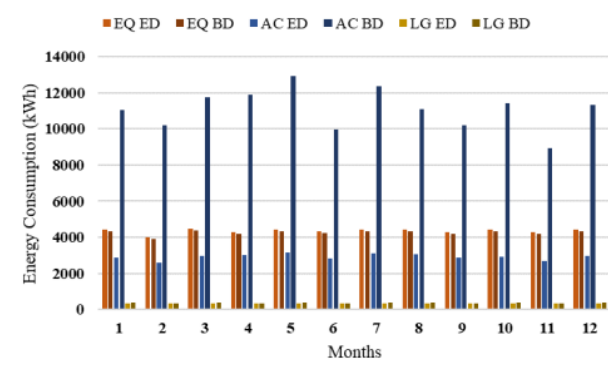

(a)

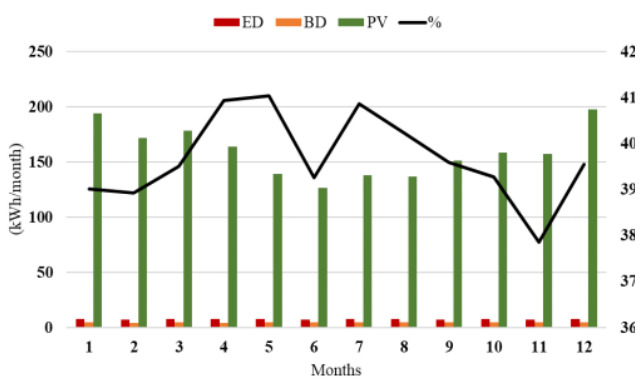

(b)

Fig. 4. Comparison of: (a) electrical energy consumed between the ED and BD case, and (b) photovoltaic (PV) generation in $\mathrm{BD}$.

Figure 5(a) shows the air temperature (AT), radiant temperature (RT), and operating temperature (OT) for both cases, and Figure 5(b) represents the relative humidity, percentage $\mathrm{PMV}$, and PPD indices. In these graphs, it is found that the OT for BD reduces by an annual average of $3.6^{\circ} \mathrm{C}$ at the urbanization level, the PMV reduces from a range of +0.20 to +1.08 to a range of -1.20 to +0.06 , and for BD meets the ranges acceptable by ASHRAE 55 [20] (0.5 to +0.5$)$ in October to March. Regarding relative humidity (RH), it was found that in $\mathrm{BD}$, it increases in all months, but in both models, there are high humidities (between $73 \%$ and $88 \%$ ). The PPD value increases in BD and exceeds, in both cases, the expected percentage of compliance recommended by ASHRAE 55 (10\%). 


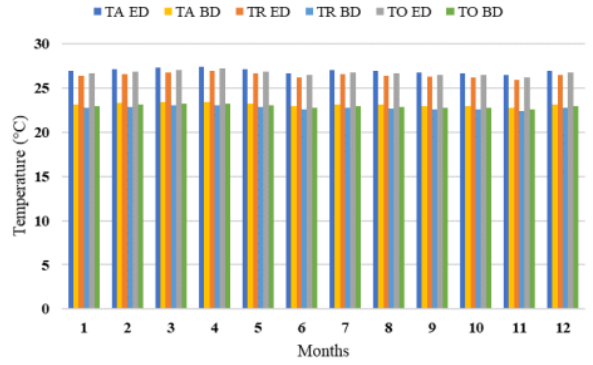

(a)

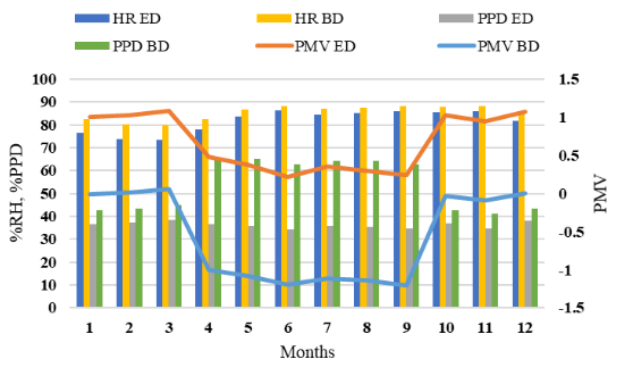

(b)

Fig. 5. Comfort indicators at urbanization level: (a) air temperature, radiant and operative, (b) relative humidity, \%PPD and PMV.

Based on these results, Table 3 presents a summary of the main architectural features in which both scenarios differ, in addition to those described in Table 2, as well as the results of thermal energy consumption and comfort presented on an annual scale.

Table 3. Comparison between the characteristics and performance of the ED and DB scenario.

\begin{tabular}{|l|c|c|}
\hline \multicolumn{1}{|c|}{ Features } & Case ED & Case BD \\
\hline Land area (hectare) & 1.13 & 10.2 \\
\hline Total surface area $\left(\mathrm{m}^{2}\right)$ & 55 & 495 \\
\hline Compactness (dimensionless) & 0.70 & 0.47 \\
\hline Eaves & No & Yes \\
\hline U-value of glazing $\left(\mathrm{W} / \mathrm{m}^{2} \mathrm{~K}\right)$ & 3.84 & 2.47 \\
\hline U-value of ceilings $\left(\mathrm{W} / \mathrm{m}^{2} \mathrm{~K}\right)$ & 4.01 & 0.156 \\
\hline Quantity of AC units & 18 & None \\
\hline Energy consumption $(\mathrm{kWh} / \mathrm{y})$ & 92 & 55 \\
\hline $\begin{array}{l}\text { Energy consumption in } \text { primary energy } \\
\left(\mathrm{kWh} / \mathrm{m}^{2} \mathrm{y}\right)\end{array}$ & 154.50 & 10.50 \\
\hline Photovoltaic generation $\left(\mathrm{kWh} / \mathrm{m}^{2} \mathrm{y}\right)$ & $\mathrm{None}$ & 363.15 \\
\hline Average annual operative temperature $\left({ }^{\circ} \mathrm{C}\right)$ & 26.95 & 23.37 \\
\hline Average annual relative humidity $(\%)$ & 81.7 & 85.3 \\
\hline Average annual PMV & 0.67 & -0.57 \\
\hline
\end{tabular}

\subsection{Zero-energy district analysis}

The total net energy of the development to determine a district definition is obtained through a numerical balance, subtracting the energy delivered to the buildings minus the energy 
exported by the buildings in terms of primary energy. For Panama, a conversion factor of 3.15 is used for electrical and renewable energy (ASHRAE 105 [21]). From this balance, it is obtained that the energy delivered for ED and BD respectively is $154 \mathrm{kWh} / \mathrm{m}^{2} \mathrm{y}$ and 10.50 $\mathrm{kWh} / \mathrm{m}^{2} \mathrm{y}$, and the energy exported can reach $363 \mathrm{kWh} / \mathrm{m}^{2} \mathrm{y}$, obtaining a balance of +353 $\mathrm{kWh} / \mathrm{m}^{2} \mathrm{y}$ for BD. Figure 6 graphically represents these values, defining the studied district as a positive net energy district, in which the demand has been exceeded.

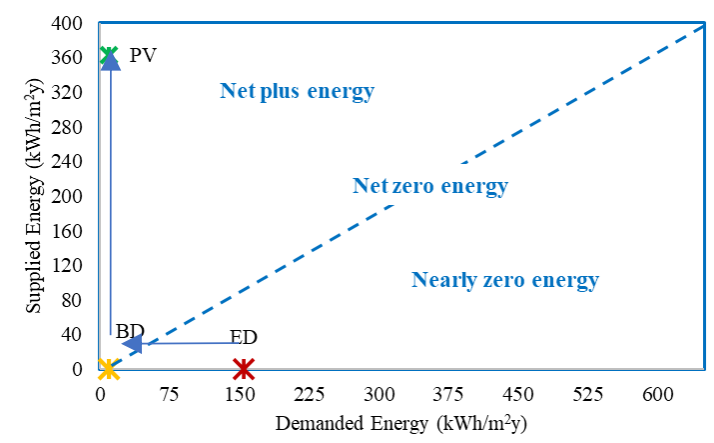

Fig. 6. District balance for its definition in terms of zero energy.

\section{Conclusions}

The first conclusions of this study are in line with a reflection of bioclimatic architecture since it is the key to achieve zero energy buildings and urbanizations. Architecture in Panama must go beyond aesthetics and economic factors. It must also consider a design that responds to the needs of energy savings and thermal comfort. The methodology and bioclimatic recommendations followed in this work open the way to determining a systematized path to define ZEDs in Panama. The need to promote natural ventilation is proven, and the use of eaves is necessary to mitigate heat gains from radiation. However, the most important aspects found here, such as the effect of increased compactness on the need for land and prices, should be further evaluated. Remembering that this is a preliminary proposal, future work can sensitize the effect of shape indicators in the design and implement other design options or low-energy active solutions to improve comfort conditions. It would also be convenient to analyze the air velocities in each building to know if they comply with the recommended bioclimatic analysis and look for a way to correct the high humidity.

Regarding the district to zero energy, it was found that, without the use of air conditioning, the energy savings that can be obtained with the passive solutions applied is $40 \%$ and that, in addition, the energy demand is only $10.50 \mathrm{kWh} / \mathrm{m}^{2} / \mathrm{y}$, which indicates that it is very close to achieving a near-zero, net-zero or positive balance with few on-site generation requirements. However, the analysis sought to evaluate the maximum generation that can be obtained in the district by placing the photovoltaic panels on the roof with the optimal orientation (south), which, when applied in the country, can be exported to the grid or nearby urbanizations, that is, a zero-energy urbanization with such a high production opens opportunities to apply smart microgrids. According to the country's proposed ambitions, the future definition of nZED in Panama will depend on further research on the subject, according to the country's proposed ambitions, evaluating the economic factors that must be considered for the generation, materials, and construction of the developments. However, this study shows that it is energetically feasible. 


\section{Acknowledgements}

This study was supported by the Panamanian Institution Secretaría Nacional de Ciencia, Tecnología e Innovación (SENACYT) https://www.senacyt.gob.pa/, under the project code FID18-056, as well as supported by the Sistema Nacional de Investigación (SNI). The authors are grateful to the Faculty of Mechanical Engineering of the Technological University of Panama for their collaboration.

\section{References}

1. Secretaría Nacional de Energía, Plan Energético Nacional 2015 - 2050, 6-348, (2016)

2. JTIA, Reglamento de edificaciones sostenibles de Panamá, (2019)

3. EPBD, Directive (EU) 2018/844 of the European parliament and the council of 30 may 2018, (2018)

4. J. Kurnitski, REHVA, How to define nearly net zero energy buildings nZEB, (2012)

5. A.R. Amaral, E. Rodrigues, A. Rodrigues, and Á. Gomes, Sustain. Cities Soc., Review on performance aspects of nearly zero-energy districts, $\mathbf{4 3}$, (2018)

6. S. Koutra et al., Sustain. The zero-energy idea in districs: Application of a methodological approach to a case study of Epinlieu (Mons), 11, (2019)

7. G.A. Osma-Pinto, D.A. Sarmiento, N.C. Barbosa Calderón, and G. Ordóñez, Dyna, Energy considerations of social dwellings in Colombia according to NZEB concept, 82, 120-130, (2015)

8. G. Mutani, M. Carroza, and V. Todeschi, Urban-Scale Energy Models: relationship between urban form and energy performance, (2020).

9. L.F. Cabeza, and M. Chàfer, Energy Build., Technological options and strategies toward zero energy buildings contributing to climate change mitigation: A systematic review, 219, (2020)

10. G. Happle, J. A. Fonseca and A. Schlueter, Energy Build., A review on occupant behavior in urban building energy models, 174, 276-292, (2018)

11. J. Natanian, O. Aleksandrowicz, and. T. Auer, Appl. Energy, A parametric approach to behavior in urban building energy models, 254, (2019)

12. M. García-Fuentes, I. González, A. Gordaliza, and C. de Torre, Proceedings, Retrofitting of a Residential District under Near Zero Energy Buildings Criteria, 1, (2017)

13. M. K. Nematchoua, Sol. Energy, From existing neighborhoods to net-zero energy and nearly zero carbon neighborhoods in the tropical regions, 211, (2020)

14. INEC, Habitantes promedios por vivienda particular en la República de Panamá, según provincia y comarca indígena, Censo de Población y Vivienda, (2010)

15. G. Gómez-Azpeitia, Bioclimarq 2016, (2016)

16. IRENA, Evaluación del Estado de Preparación de las Energías Renovables: Panamá, (2018)

17. ABB, Cuaderno de aplicaciones técnicas $n^{\circ} 10$. Plantas fotovoltaicas, 22, (2011)

18. R. Liggett, M. Milne, C. Gómez, D. Leeper, A. Benson, and Y. Bhattacharya, Climate Consultant 6.0, (2016)

19. Secretaría Nacional de Energía, Guía de construcción sostenible para el ahorro de energía en edificaciones (Panamá), 1-53, (2016)

20. ASHRAE, ANSI/ASHRAE Stand. 55, Thermal environmental conditions for human occupancy, 7, (2017)

21. ASHRAE, ANSI/ASHRAE Stand. 105, Standard methods of determining, expressing, and comparing building energy performance and greenhouse gas emissions, (2014) 